\title{
Investigation of Electromagnetic Shielding and Solar Properties of Woven Fabrics made by Barium titanate/Polyester Bicomponent Yarns
}

\author{
Rumeysa Celen, Yusuf Ulcay \\ Bursa Uludag University/ Faculty of Engineering/ Department of Textile Engineering
}

Corresponding Author: Rumeysa Celen, rumeysa@uludag.edu.tr

\begin{abstract}
In this study, electromagnetic shielding and solar properties of woven fabrics which were produced barium titanate/polyester bicomponent yarns were investigated. 1, 2 and 3\% additive ratios of barium titanate and three different fabric structures (1/1 plain, sateen and special weave) were used in the experiments. The effect of additive ratio and the fabric structure on sheet resistance and electromagnetic shielding properties were evaluated. Electromagnetic Shielding Effectiveness (EMSE) of the woven fabrics was determined according to the ASTM D4935-10 standard by using coaxial transmission line measurement technique in the frequency range of $15-3000 \mathrm{MHz}$. The fabric with the highest content of the barium titanate (3\%) and special weave showed the highest shielding effectiveness, reaching $13.96 \mathrm{~dB}$ at $15 \mathrm{MHz}$. The solar properties were measured according to EN14500 using a UV/VIS/NIR spectrophotometer and results were calculated according to EN 410 standard. The reflectance values of barium titanate added polyester fabrics increased and the transmittance values decreased.
\end{abstract}

\author{
ARTICLE HISTORY \\ Received: 16.10.2019 \\ Accepted: 14.10 .2020
}

\section{KEYWORDS}

Barium titanate, bicomponent yarn, woven fabric, electromagnetic shielding effectiveness, solar property.

\section{INTRODUCTION}

With the advancement of wireless technology, electronic devices become indispensable parts of our daily lives. These devices raise different radiations in different frequency bands [1]. The electronic devices are capable of emitting electromagnetic waves that will result in some electromagnetic interference (EMI) troubles [2, 3, 4]. Electromagnetic interference (EMI) shielding is a process of limiting the penetration of electromagnetic rays into a space by blocking them by a barrier made of conductive material. It is a very popular method of protecting electronic and electrical equipment and even people against electromagnetic radiation. The material or protector which protects a body, environment or circuit from harmful electromagnetic radiation is called a shield. Shields are used either to isolate a space from outside sources of electromagnetic radiation or to prevent the unwanted emission of electromagnetic energy radiated by internal sources [5].

The EMI phenomena can be viewed as a kind of environmental pollution of the electromagnetic spectrum [6, 7]. It is one of the major problems to be resolved. Various researchers and industrial companies have shown keen interest in providing solutions to overcome this problem. Among the various solutions offered, textile products and textile-based composite materials have caught the attention of researchers [8, 9]. In recent years, conductive fabrics have been considered for electromagnetic shielding and anti-electrostatic purposes in various applications for the defense, electrical, and electronic industries. This is mainly due to their desirable properties in terms of flexibility, electrostatic discharge, EMI protection, radio frequency interference protection, thermal expansion matching, and weight [10]. In the literature, there are many studies about

To cite this article: Celen R, Ulcay Y. 2020. Investigation of Electromagnetic Shielding and Solar Properties of Woven Fabrics made by Barium titanate/Polyester Bicomponent Yarns. Tekstil ve Konfeksiyon, 30(4), 251-261. 
conductive textiles and their electromagnetic shielding applications [11-17 etc.]

In the advancement of EM wave absorber technology, wide variety of materials have received much attention, such as dielectric/magnetic materials [18-25] and conducting polymers [26-29]. Barium titanate (BaTiO3) is a member of the perovskite compounds family has ferroelectric properties with high dielectric constants [30]. Due to its unique properties (mechanical and chemically stable, high dielectric constant, etc.), barium titanate is one of the most important ferroelectric materials studied in a wide range [31]. Among other ferroelectrics, BaTiO3 is a wellreferenced, relatively cheap to produce, and lead-free material $[32,33]$. In the literature, there are some studies about electromagnetic shielding properties of barium titanate additive textile structures and the results of these studies are promising. Most of these studies have focused on the composite structures [26, 34, 35] and also in the literature, there is a gap in the use of barium titanate in conductive fiber/yarn production. However, there are limited studies about the solar properties of barium titanate and these studies focused on barium titanate added composites and film structures [36-38].

In our previous study [39], mechanical properties and electrical conductivity properties of barium titanate/ polyester bicomponent yarns were investigated. Knitted fabrics were produced from bicomponent yarns with two different fabric densities using a circular knitting machine. The effects of additive ratio and the fabric density on electromagnetic shielding efficiency (EMSE) were investigated. In the present study, woven fabrics were produced from the same bicomponent yarns with three different fabric constructions (plain, sateen and special weave). EMSE performance of the fabrics was determined according to the ASTM D4935-10 standards by using a coaxial transmission line measurement technique in the frequency range of 15-3000 $\mathrm{MHz}$. The effect of additive ratio and the fabric weave type on EMSE were investigated. Besides EMSE properties, solar properties of woven fabrics were also evaluated in the $280-2500 \mathrm{~nm}$ range of the electromagnetic spectrum. For the first time, electromagnetic shielding and solar properties of barium titanate added textiles were evaluated together.

\section{MATERIAL AND METHOD}

\subsection{Bicomponent Yarns}

Barium titanate/polyester (core/sheath) bicomponent yarns were used in the study. Bicomponent yarns were spun using the Spinboy melt spinning machine. Three different adding ratios of the barium titanate masterbatch $(1 \%, 2 \%$ and $3 \%)$ were tested. The core/sheath ratio was 30/70. Bicomponent yarns consist of 72 filaments.

Optical microscope images of bicomponent yarns were taken with Projectina optical microscope with an objective of $40 \mathrm{X}$. Scanning electron microscope (SEM) images of bicomponent yarns were taken with Carl Zeiss / Gemini 300. The magnification rate was chosen as $2000 \mathrm{X}$ and 3000 $X$. Differential scanning calorimeter (DSC) thermal analysis of reference (\%100 polyester) and bicomponent yarns were carried out on a Mettler Toledo DSC 823 according to ISO 11357-7 standard. To determine the inorganic (barium titanate) content of bicomponent yarns, $\%$ ash content test was applied according to the ASTM D5630-01 standard. Three measurements were taken for each bicomponent yarn, and the average $\%$ ash content was calculated.

\subsection{Woven Fabrics}

The woven fabrics used in this study were successfully produced on a dobby weaving machine (DORNIER $\left.{ }^{\circledR}\right)$. The woven fabrics with $1 / 1$ plain, sateen and special weave were made using the three different additive ratios of the bicomponent yarns. Fabric weave types were shown in Figure 1 schematically.

The properties of the reference and woven fabrics were given in Table 1. Mass per unit area measurements were carried out by the TS 251 standard. Each sample was weighed three times on a precision scale, and the average value was calculated. Thickness measurements were made according to TS 7128 EN ISO 5084 standard with James Heal's R \& B Cloth thickness tester. Three measurements were taken for each fabric, and the average thickness values were calculated.

Optical microscope images were taken with Mshot MS 60 digital microscope instrument. Figure 2 showed the optical images of $1 \mathrm{~B}, 1 \mathrm{~S}$ and $1 \mathrm{O}$ coded fabrics.
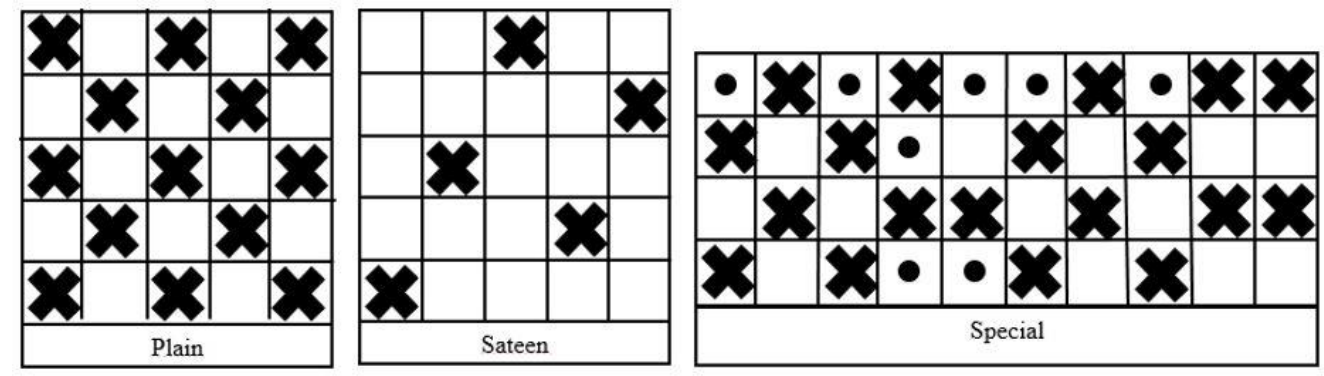

Figure 1. Schematic view of woven fabrics 
Table 1. Specifications of the woven fabrics

\begin{tabular}{|c|c|c|c|c|c|c|}
\hline Fabric Code & $\begin{array}{l}\text { Yarn Count } \\
\text { (dtex) }\end{array}$ & $\begin{array}{c}\text { Warp } \\
\text { Density }(1 / \mathrm{cm})\end{array}$ & $\begin{array}{l}\text { Weft density } \\
(1 / \mathrm{cm})\end{array}$ & $\begin{array}{l}\text { Mass per unit } \\
\text { area }\left(\mathrm{g} / \mathrm{m}^{2}\right)\end{array}$ & $\begin{array}{c}\text { Fabric } \\
\text { Thickness }(\mathrm{mm})\end{array}$ & Constructions \\
\hline REF-B & 260 & & & 157 & 0.31 & 1/1 Plain \\
\hline 1B & 261 & & & 192 & 0.37 & 1/1 Plain \\
\hline $2 \mathrm{~B}$ & 261 & & & 192 & 0.41 & 1/1 Plain \\
\hline $3 \mathrm{~B}$ & 263 & & & 195 & 0.40 & 1/1 Plain \\
\hline REF-S & 260 & & & 157 & 0.35 & Sateen \\
\hline $1 \mathrm{~S}$ & 261 & & & 184 & 0.47 & Sateen \\
\hline $2 \mathrm{~S}$ & 261 & 45 & 18 & 180 & 0.47 & Sateen \\
\hline $3 \mathrm{~S}$ & 263 & & & 183 & 0.48 & Sateen \\
\hline REF-O & 260 & & & 156 & 0.39 & Special \\
\hline 10 & 261 & & & 189 & 0.52 & Special \\
\hline $2 \mathrm{O}$ & 261 & & & 187 & 0.55 & Special \\
\hline 30 & 263 & & & 189 & 0.52 & Special \\
\hline
\end{tabular}

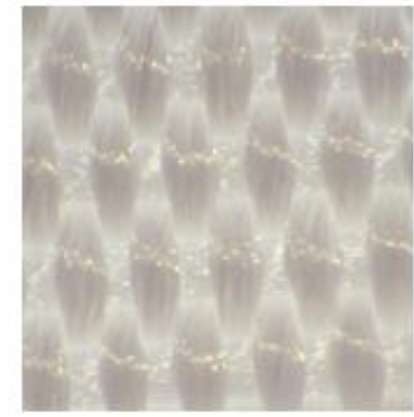

1B

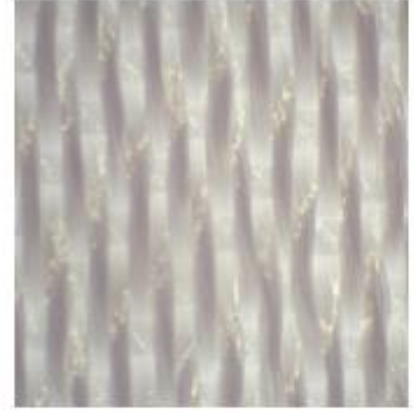

1S

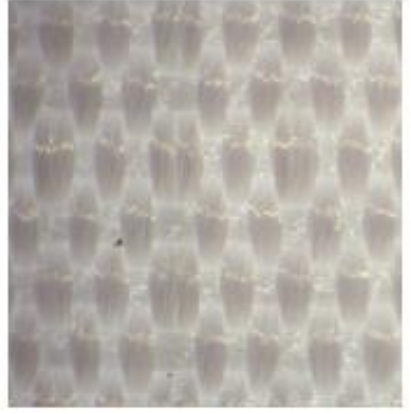

10

Figure 2. Optical images of woven fabrics

\subsection{Sheet Resistance and Electromagnetic Shielding Effectiveness Measurement}

The sheet resistance of the fabrics was measured ENTEK Electronics Four Point Probe instrument. Ten measurements were taken for each fabric, and the average sheet resistance values were calculated.

EMSE of woven fabrics was determined according to the ASTM D4935-10 standards by using coaxial transmission line measurement technique in the frequency range of 15$3000 \mathrm{MHz}$. The compact testing equipment (ElectroMetrics Inc., model EM-2107 A) (Figure 3) was utilized to measure the EMSE of the materials. Woven fabrics were conditioned at $20^{\circ} \mathrm{C} \pm 2{ }^{\circ} \mathrm{C}$ temperature and $65 \% \pm 2 \%$ relative humidity. Measurements were repeated three times on different areas of the fabrics and the average values of the measurements were calculated according to Equation (1)

$S E[d B]=20 \log \frac{E_{0}}{E_{1}}$

where $E_{0}$ is measured without the fabric sample and $E_{1}$ is measured with the fabric sample on the test area.
Requirements for electromagnetic shielding textiles are specified and classified (Table 2) by the Functional Technical Textiles Standard [40]. To test the EMSE of the textiles, the coaxial transmission line method specified in ASTM D 4935 was referred to in this classification. According to this standard, professional uses include medical equipment, quarantine material, professional security uniform for an electronic manufacturer, electronic kit, or other new applications; general uses include casual wear, office uniform, maternity dress, apron, consumptive electronic products, and communication-related products.

\subsection{Spectroscopic Analysis}

The solar properties of the fabrics were examined with measurements that performed with Shimadzu UV-3600 Plus spectrophotometer with an integrating sphere at the range of 280-2500 $\mathrm{nm}$. Transmission and reflection were measured and the results were calculated with an excel program according to EN 410 standard. The visible transmittance $\left(\mathrm{T}_{\mathrm{V}}: 380-780 \mathrm{~nm}\right)$, visible reflectance $\left(\mathrm{R}_{\mathrm{V}}\right.$ : 380-780 nm), solar transmittance (TS: 300-2500), solar reflectance ( $\mathrm{R}_{\mathrm{S}}$ : 300-2500) and UV transmittance (T $\mathrm{T}_{\mathrm{UV}}$ : 280-380 nm) were calculated by using Equations (2-6) according to the EN 410 standard. 


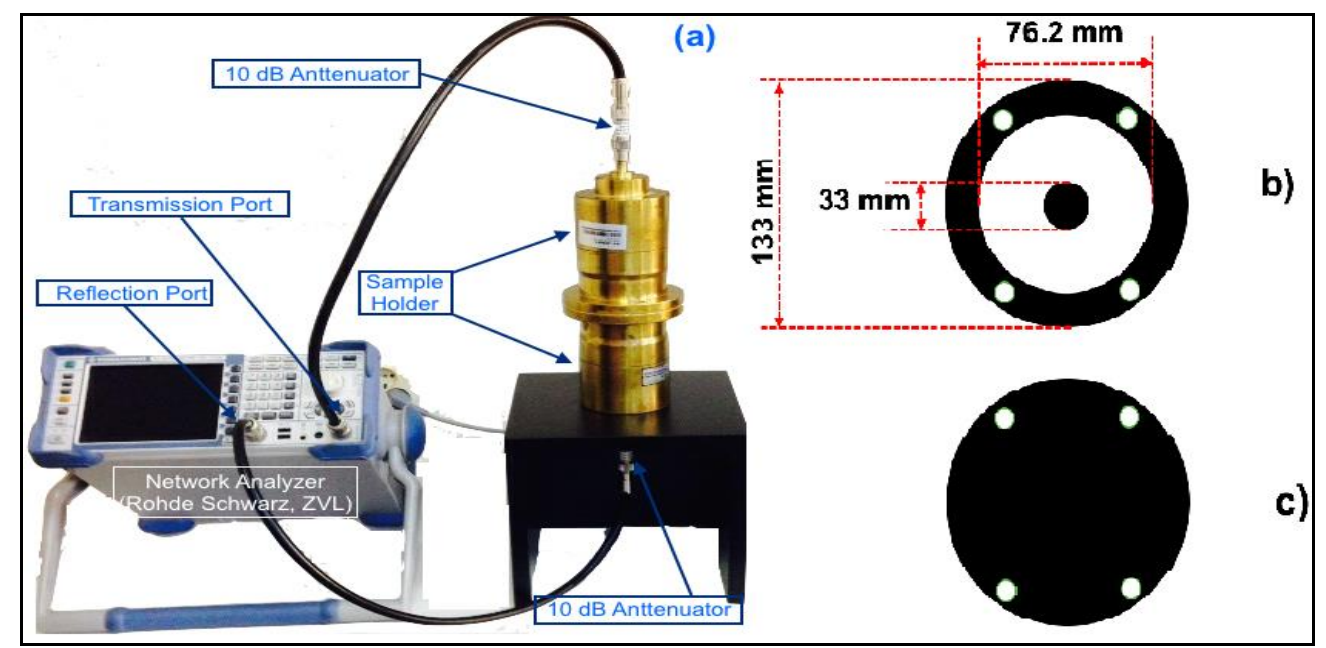

Figure 3. EMSE test instrument, (a) Set up of the EMSE testing apparatus; (b) and (c) Specimen for reference and load, respectively.

Table 2. Functional technical textile standard [40]

\begin{tabular}{llll}
\hline Type & Grade & Shielding Effectiveness [dB] & Classification \\
\hline & AAAAA & SE $>60 \mathrm{~dB}$ & Excellent \\
Class I & AAAA & $60 \mathrm{~dB} \geq \mathrm{SE}>50 \mathrm{~dB}$ & Very Good \\
[Professional Use] & AAA & $50 \mathrm{~dB} \geq \mathrm{SE}>40 \mathrm{~dB}$ & Good \\
& AA & $40 \mathrm{~dB} \geq \mathrm{SE}>30 \mathrm{~dB}$ & Moderate \\
& A & $30 \mathrm{~dB} \geq \mathrm{SE}>20 \mathrm{~dB}$ & Fair \\
Class II & AAAAA & SE $>30 \mathrm{~dB}$ & Excellent \\
[General Use] & AAAA & $30 \mathrm{~dB} \geq \mathrm{SE}>20 \mathrm{~dB}$ & Very Good \\
& AAA & $20 \mathrm{~dB} \geq \mathrm{SE}>10 \mathrm{~dB}$ & Good \\
& AA & $10 \mathrm{~dB} \geq \mathrm{SE}>7 \mathrm{~dB}$ & Moderate \\
\hline
\end{tabular}

$T_{V}(\%)=\frac{\sum_{\lambda=\mathbb{8 s 0}}^{780} D_{\lambda} \tau(\lambda) V(\lambda) \Delta \lambda}{\sum_{\lambda=880}^{780} D_{\lambda} V(\lambda) \Delta \lambda}$

$R v(\%)=\frac{\sum_{\lambda=880}^{780} D_{\lambda} \rho(\lambda) v(\lambda) \Delta \lambda}{\sum_{\lambda=880}^{780} D_{\lambda} v(\lambda) \Delta \lambda}$

$\operatorname{Ts}(\%)=\frac{\sum_{\lambda=800}^{2500} s_{\lambda} \tau(\lambda) \Delta \lambda}{\sum_{\lambda=\sin }^{2500} S_{\lambda} \Delta \lambda}$

$R s(\%)=\frac{\sum_{\lambda=800}^{2500} s_{\lambda} \rho(\lambda) \Delta \lambda}{\sum_{\lambda=800}^{2500} s_{\lambda} \Delta \lambda}$

$T_{U V}(\%)=\frac{\sum_{\lambda=280}^{380} U_{\lambda} \tau(\lambda) \Delta \lambda}{\sum_{\lambda=280}^{380} U_{\lambda} \Delta \lambda}$

where $D \lambda$ is relative spectral distribution of illuminant D65, $\tau(\lambda)$ is the spectral transmittance of the material, $V(\lambda)$ is the spectral luminous efficiency for photonic vision, $\Delta \lambda$ is the wavelength interval, $\rho(\lambda)$ is the spectral reflectance of the material, $S \lambda$ is the relative spectral distribution of the solar radiation and $U \lambda$, is the relative distribution of the UV part of the global solar radiation [41].

\section{RESULTS AND DISCUSSION}

\subsection{Characterization Results of Bicomponent Yarns}

Table 3 showed the $\%$ ash content of bicomponent samples. With this analysis, an inorganic additive ratio (\%) was observed. Ash values of bicomponent samples were almost consistent with applied additive ratios.

Table 3. Ash content of samples

\begin{tabular}{lc}
\hline Description & Ash Content $[\%]$ \\
\hline $1 \% \mathrm{BaTiO}_{3}$ additive bicomponent yarn & 1.02 \\
$2 \% \mathrm{BaTiO}_{3}$ additive bicomponent yarn & 1.91 \\
$3 \% \mathrm{BaTiO}_{3}$ additive bicomponent yarn & 2.88 \\
\hline
\end{tabular}

Optical cross-section images and SEM images of bicomponent yarns were given in Figures 4 and 5, respectively. The core-sheath structure of bicomponent yarns was seen obviously. It was seen that bicomponent yarns had homogenous structures.

DSC analysis of the barium titanate additive bicomponent yarns and reference polyester yarn was given in Figure 6. In the DSC graphic, an endothermic melting peak belonging to the polyester was observed at approximately $250{ }^{\circ} \mathrm{C}$. The melting began at $246{ }^{\circ} \mathrm{C}$ and finished at $259^{\circ} \mathrm{C}$ in the DSC graph of the reference polyester yarn. The increase of $8{ }^{\circ} \mathrm{C}$ for the melting point of the melting curve of the $3 \%$ additive bicomponent yarn was evaluated to reflect the effect of the barium titanate on the melting temperature. No 
peak related to the barium titanate, which does not degrade below $1650^{\circ} \mathrm{C}$, was observed.

\subsection{Sheet Resistance and Electromagnetic Shielding Effectiveness Test Results}

It is well known that electrical conductivity depends on the amount of the conductive component. The electrical conductivity is inversely proportional to the sheet resistance. The effect of the additive ratio and fabric type on the sheet resistance of woven fabrics was investigated, and it was shown graphically in Figure 7. Sheet resistance values decreased slightly, with an increasing additive ratio. Consistent with previous studies [26, 34, 49], barium titanate additive decreased electrical resistance. Fabric weave type did not affect sheet resistance significantly. The lowest sheet resistance was $125 \mathrm{M} \Omega / \mathrm{sq}$ for the $3 \mathrm{~S}$ coded sample.

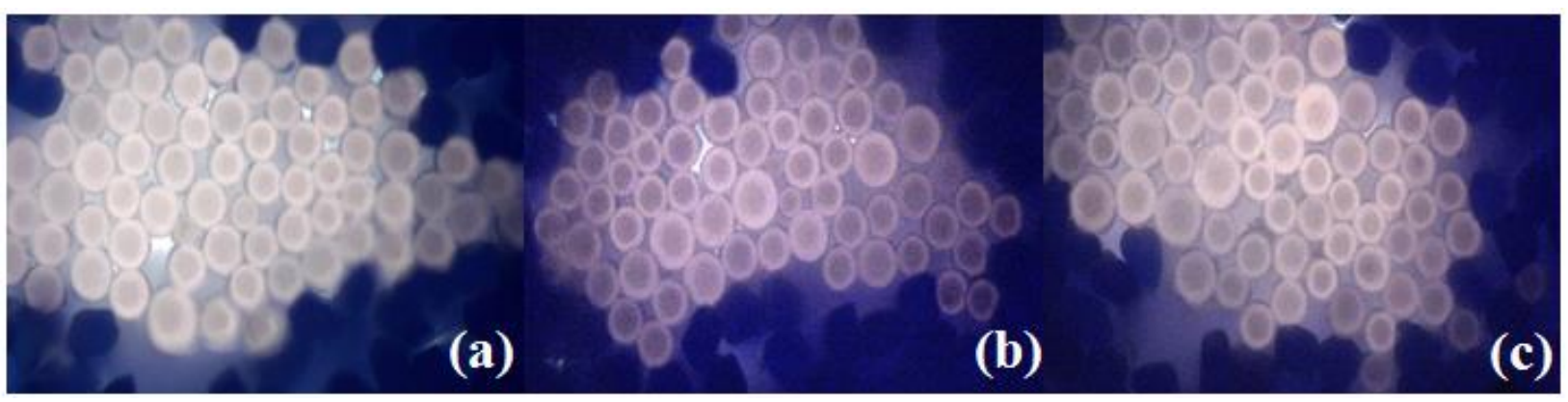

Figure 4. Optical cross-section images of bicomponent yarns; (a) $1 \% \mathrm{BaTiO}_{3}$ additive, (b) $2 \% \mathrm{BaTiO}_{3}$ additive, (c) $3 \% \mathrm{BaTiO}_{3}$ additive $(\mathrm{Mag}=40 \mathrm{X})$

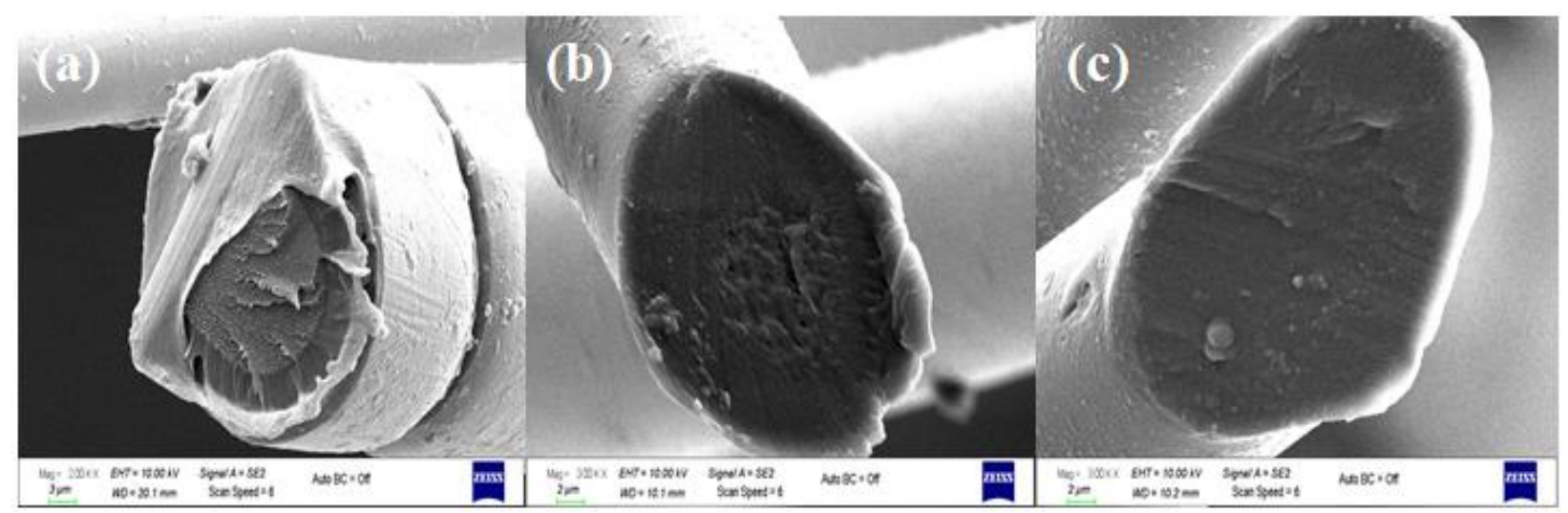

Figure 5. SEM images of bicomponent yarns; (a) $1 \% \mathrm{BaTiO}_{3}$ additive (Mag= 2000X), (b) $2 \% \mathrm{BaTiO}_{3}$ additive (Mag= 3000X), (c) $3 \%$ $\mathrm{BaTiO}_{3}$ additive $(\mathrm{Mag}=3000 \mathrm{X})$

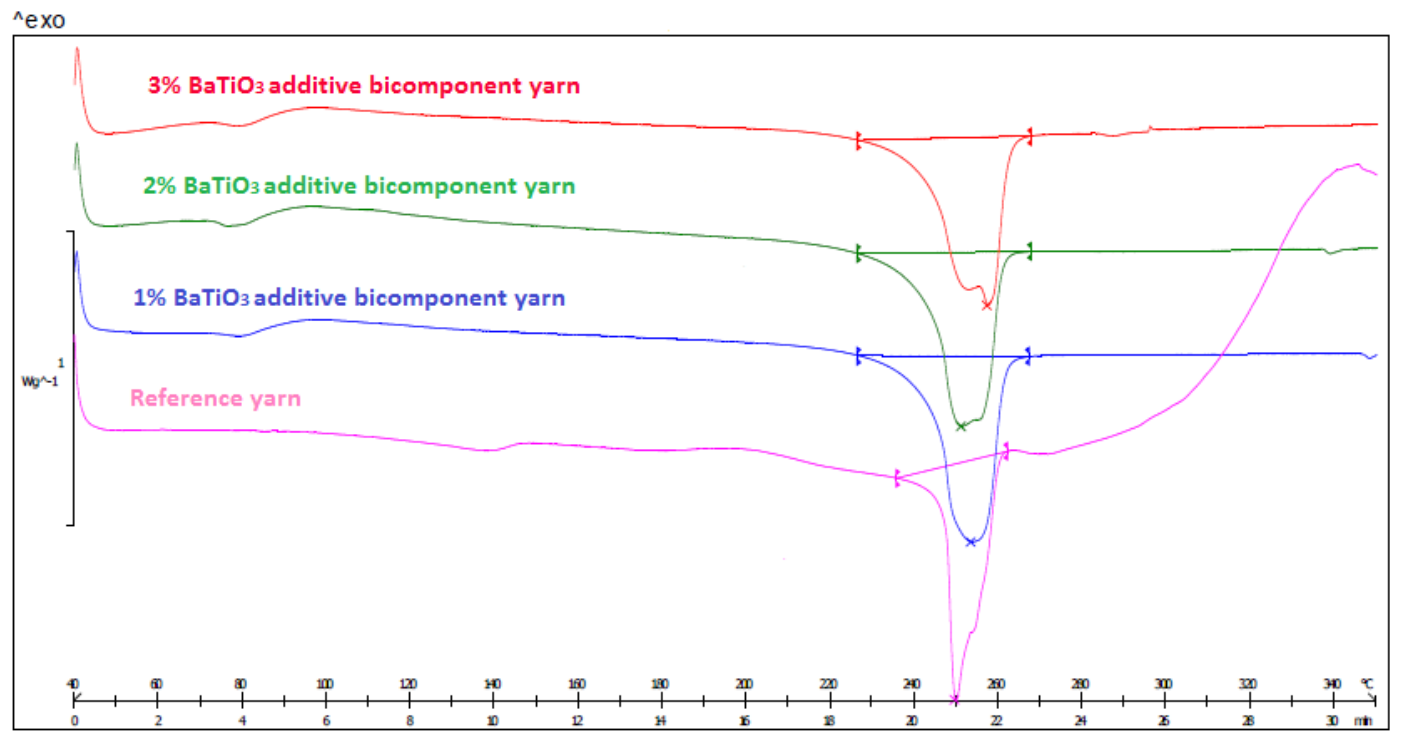

Figure 6. DSC analysis of yarns 


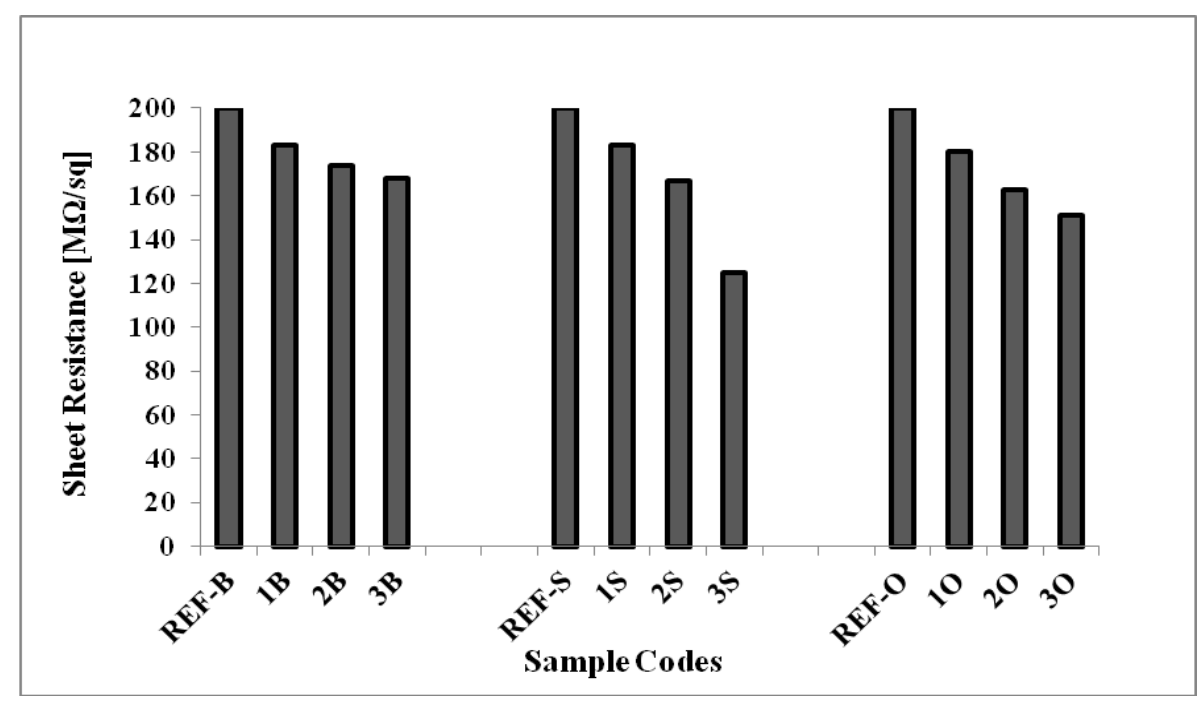

Figure 7. Sheet resistance test results

EMSE results of fabrics at $15 \mathrm{MHz}$ were summarized in Table 4. Figure 8 displayed the EMSE values of REF-B, $1 \mathrm{~B}, 2 \mathrm{~B}$ and $3 \mathrm{~B}$ coded plain fabrics with the frequency in the range from $15 \mathrm{MHz}$ to $315 \mathrm{MHz}$. Although the measurements were performed in $15-3000 \mathrm{MHz}$ frequency range, shielding efficiency values were $0 \mathrm{~dB}$ after 315 MHz. Therefore, the graphics only covered the frequency range at $15-315 \mathrm{MHz}$. The shielding effectiveness values of the reference fabrics (REF-B, REF-S and REF-O) produced with $100 \%$ polyester yarns were found to be $0-2 \mathrm{~dB}$, as could be seen in Figures 8, 9 and 10. It is well known that polymers are generally insulating materials and can not shield the electromagnetic waves. The $\mathrm{SE}$ values of $1 \mathrm{~B}, 2 \mathrm{~B}$ and 3B were in the range of 4-7 $\mathrm{dB}$ until $45 \mathrm{MHz}$. The highest SE values were recorded 11.93, 11.98 and $12.32 \mathrm{~dB}$ at $15 \mathrm{MHz}$ for $1 \mathrm{~B}, 2 \mathrm{~B}$ and $3 \mathrm{~B}$ coded fabrics.

Table 4. EMSE results

\begin{tabular}{lc}
\hline Fabric codes & EMSE $[\mathrm{dB}], \mathrm{f}=15 \mathrm{MHz}$ \\
\hline REF-B & 0.94 \\
1B & 11.93 \\
2B & 11.98 \\
3B & 12.32 \\
REF-S & 0.95 \\
\hline
\end{tabular}

\begin{tabular}{lc}
\hline $1 \mathrm{~S}$ & 13.23 \\
$2 \mathrm{~S}$ & 13.03 \\
$3 \mathrm{~S}$ & 13.44 \\
$\mathrm{REF}-\mathrm{O}$ & 0.93 \\
$1 \mathrm{O}$ & 13.93 \\
$2 \mathrm{O}$ & 13.90 \\
$3 \mathrm{O}$ & 13.96 \\
\hline
\end{tabular}

Figure 9 displayed the EMSE values of REF-S, 1S, 2S and $3 \mathrm{~S}$ coded sateen fabrics with the frequency range from 15 $\mathrm{MHz}$ to $315 \mathrm{MHz}$. The SE values of $1 \mathrm{~S}, 2 \mathrm{~S}$ and $3 \mathrm{~S}$ were in the range of 4-8 $\mathrm{dB}$ until $45 \mathrm{MHz}$. The highest $\mathrm{SE}$ values were recorded $13.23,13.03$ and $13.44 \mathrm{~dB}$ at $15 \mathrm{MHz}$ for $1 \mathrm{~S}$, $2 \mathrm{~S}$ and $3 \mathrm{~S}$ coded fabrics.

Figure 10 displayed the EMSE values of REF-O, 1O, 20 and $3 \mathrm{O}$ coded special weave fabrics with the frequency range from $15 \mathrm{MHz}$ to $315 \mathrm{MHz}$. The SE values of $1 \mathrm{O}, 2 \mathrm{O}$ and 30 were in the range of $4-9 \mathrm{~dB}$ until $60 \mathrm{MHz}$. The highest SE values were recorded 13.93, 13.90 and $13.96 \mathrm{~dB}$ at $15 \mathrm{MHz}$ for $1 \mathrm{O}, 2 \mathrm{O}$ and $3 \mathrm{O}$ coded fabrics. 


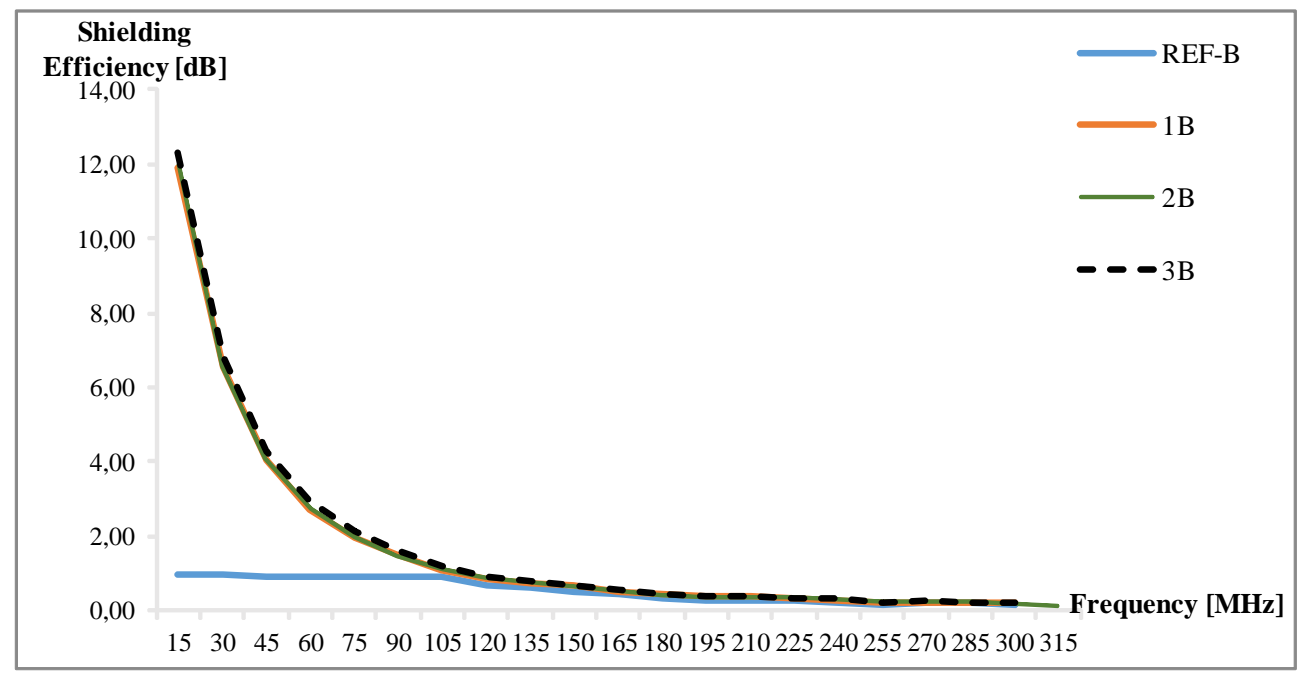

Figure 8. EMSE results of plain weave fabrics

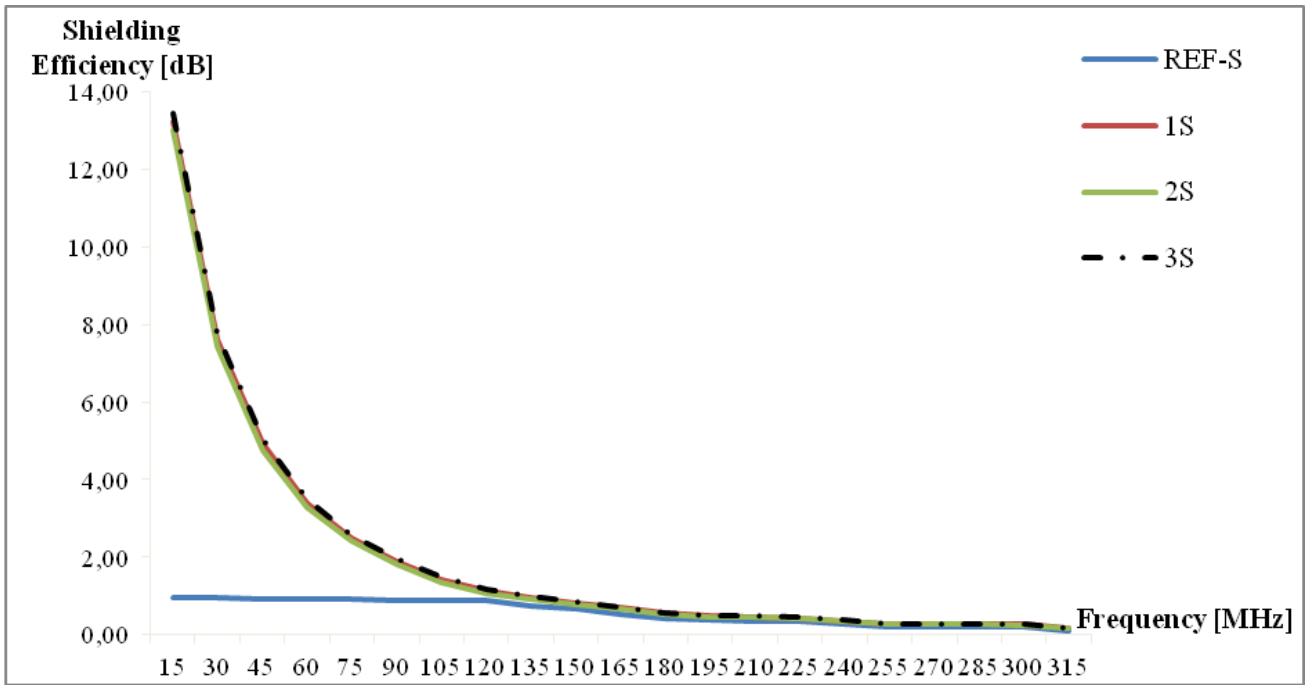

Figure 9. EMSE results of sateen weave fabrics

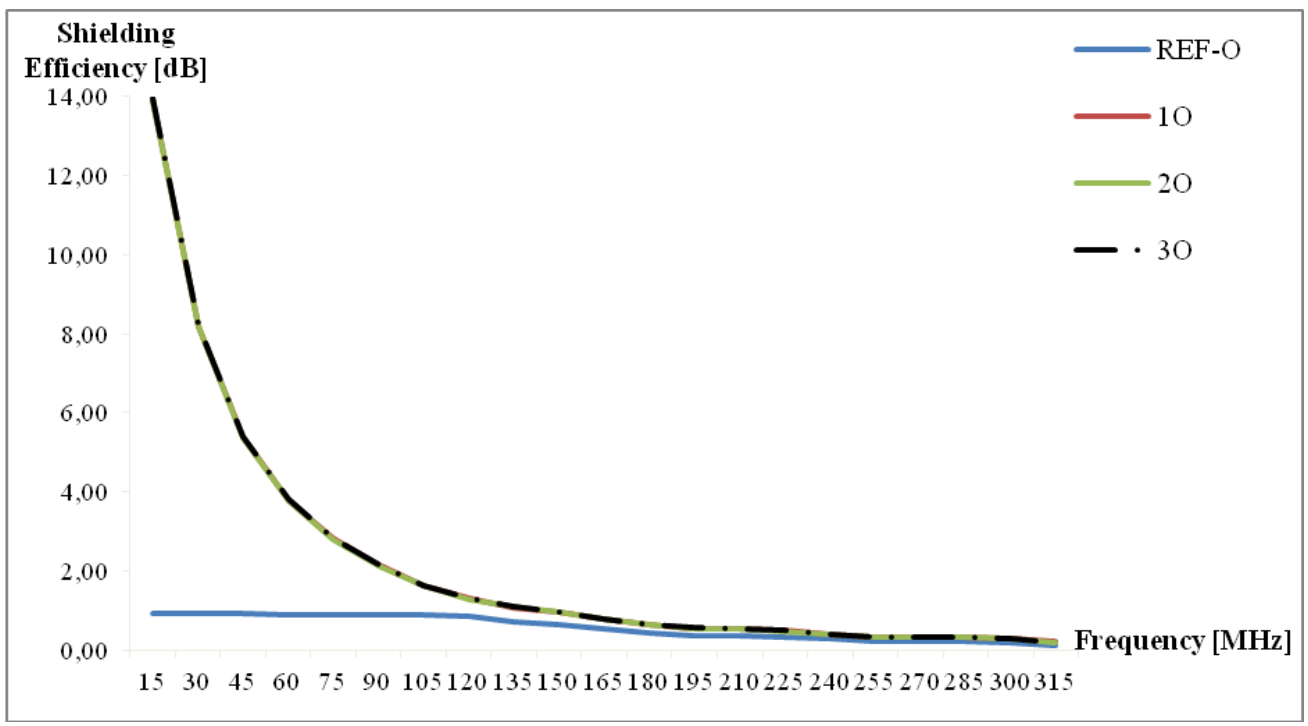

Figure 10. EMSE results of special weave fabrics 
Additive concentration is a parameter that affects the SE values of fabrics. In the literature, the effect of additive concentration on EMSE results was investigated [42, 43, etc.]. However, when different barium titanate concentrations were compared at the same fabric structure, all samples had close EMSE values. This situation was the same in different fabric weave types. There was no significant change between the concentrations tested. SE results of fabrics showed that SE values generally have a decreasing tendency depending on the increasing frequency. Previous studies stated that fabric structures have higher EMSE in low frequencies [44-46].

Fabric weave type is a parameter that affects the SE values of fabrics. In the literature, the effect of fabric weave type on EMSE results was investigated [15, 47, 48, etc.]. To evaluate the effect of fabric weave type on shielding efficiency of woven fabrics with the same additive ratio but different woven structures, the shielding efficiency values of coded fabrics were given in Figures 11, 12 and 13, respectively. When Figures 11, 12 and 13 were examined, while special weave fabrics had the highest shielding efficiency, plain weave fabrics had the lowest shielding efficiency for each additive ratio. Shielding efficiency values of sateen fabrics were close to special weave but slightly lower. The highest SE values were recorded 13.93, 13.90 and $13.96 \mathrm{~dB}$ at $15 \mathrm{MHz}$ for $1 \mathrm{O}, 2 \mathrm{O}$ and $3 \mathrm{O}$ coded fabrics, respectively. The SE values of all samples were above $5 \mathrm{~dB}$ until $45 \mathrm{MHz}$. It was found that barium titanate affected the electromagnetic shielding properties of fabric samples. Consistent with our previous study [39], EMSE values of fabrics increased compared to the reference fabrics.

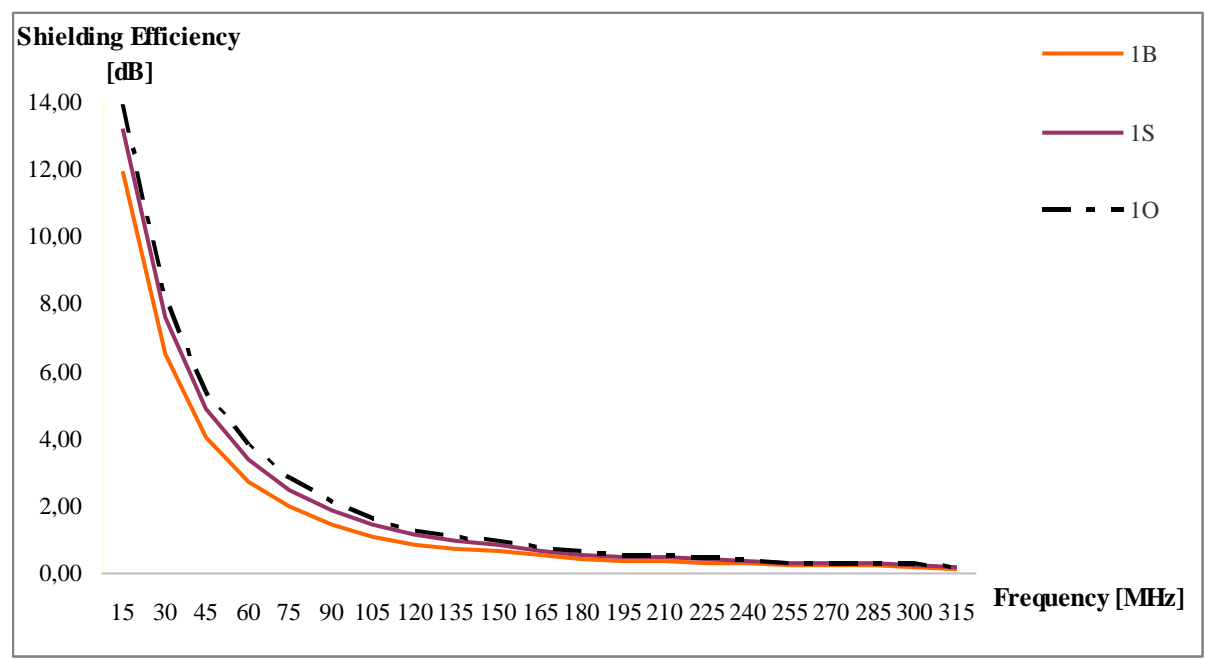

Figure 11. Effect of fabric weave type on EMSE results for $1 \%$ additive ratio

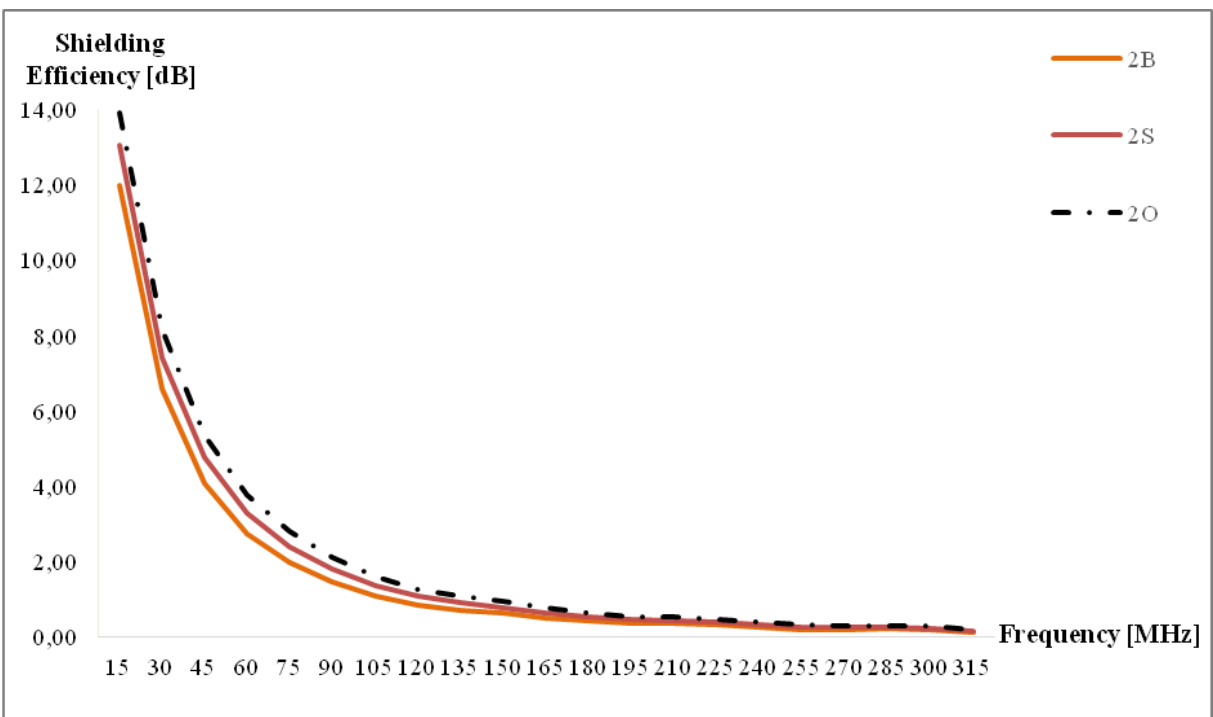

Figure 12. Effect of fabric weave type on EMSE results for $2 \%$ additive ratio 


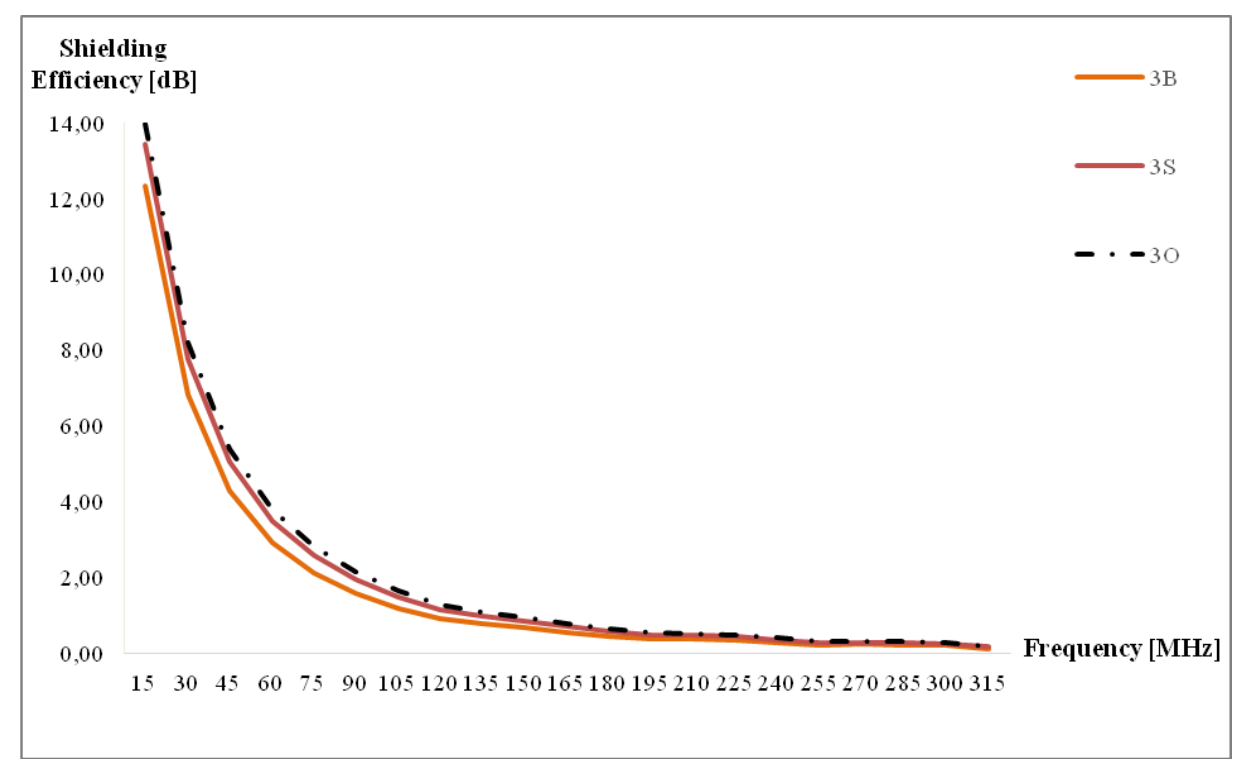

Figure 13. Effect of fabric weave type on EMSE results for 3\% additive ratio

The range of $20 \mathrm{~dB} \geq \mathrm{SE}>10 \mathrm{~dB}$ EMSE is classified as "good" and $10 \mathrm{~dB} \geqslant \mathrm{SE}>7 \mathrm{~dB}$ EMSE is classified as "moderate" in "General Use" by The Functional Technical Textiles Standard. SE values of the woven fabrics were "good" at $15 \mathrm{MHz}$ and they were "moderate" up to $45 \mathrm{MHz}$. When it was considered in conjunction with the previous studies [26, 49-51], barium titanate could be a promising electromagnetic shielding material. However, using barium titanate alone in the woven fabric structure did not provide sufficient SE for general use.

\subsection{Spectrophotometry Results}

The spectrophotometry results of fabrics were given in Table 5. It was observed that when wavelength was between 280 and $2500 \mathrm{~nm}$, ultraviolet, visible and solar transmittance values of woven fabrics decreased with barium titanate additive. Similarly, in the study of Cai et. al. [38], the transmittance values reduced, even for the lowest barium titanate concentration (1\%) compared to the reference fabrics for each fabric weave type.

When the transmittance results of plain weave fabrics were investigated, it was shown that $\mathrm{UV}$ transmittance $\left(\mathrm{T}_{\mathrm{UV}}\right)$ values decreased by $78 \%$, the visible transmittance $\left(\mathrm{T}_{\mathrm{V}}\right)$ values decreased by $19 \%$, the solar transmittance $\left(\mathrm{T}_{\mathrm{S}}\right)$ values decreased by $16 \%$ for $3 \%$ barium titanate additive ratio compared to REF-B coded fabric, respectively. The lowest ultraviolet, visible and solar transmittance values $2.14 \%, 30.39 \%$ and $31.94 \%$ were obtained at maximum barium titanate additive ratio. When the results of sateen weave fabrics were investigated, it was shown that UV transmittance ( $\mathrm{T}_{\mathrm{UV}}$ ) values decreased by $77 \%$, the visible transmittance $\left(\mathrm{T}_{\mathrm{V}}\right)$ values decreased by $16 \%$, the solar transmittance $\left(\mathrm{T}_{\mathrm{S}}\right)$ values decreased by $11 \%$ for $3 \%$ barium titanate additive ratio compared to REF-S coded fabric, respectively. The lowest ultraviolet, visible and solar transmittance values $2.21 \%, 29.35 \%$ and $30.93 \%$ were obtained at maximum barium titanate additive ratio. When the results of special weave fabrics were investigated, it was shown that UV transmittance ( $\mathrm{T}_{\mathrm{UV}}$ ) values decreased by $80 \%$, the visible transmittance $\left(\mathrm{T}_{\mathrm{V}}\right)$ values decreased by $23 \%$, the solar transmittance $\left(\mathrm{T}_{\mathrm{S}}\right)$ values decreased by $19 \%$ for $3 \%$ barium titanate additive ratio compared to REF-O coded fabric, respectively. The lowest ultraviolet, visible and solar transmittance values $2.10 \%, 29.34 \%$ and $31.03 \%$ were obtained at maximum barium titanate additive ratio. However, the transmittance values slightly reduced with increasing barium titanate concentration for each fabric weave type.

In contrast with transmittance values, it was observed that visible and solar reflectance values of fabrics increased with barium titanate additive. Similarly, in the the study of Xiang and Zhang [37], the reflectance values increased even for the lowest barium titanate concentration (1\%) compared to the reference fabrics for each fabric weave type. When the reflectance results of plain weave fabrics were investigated, it was shown that visible reflectance $\left(\mathrm{R}_{\mathrm{V}}\right)$ values increased by $15 \%$ and the solar reflectance $\left(\mathrm{R}_{\mathrm{S}}\right)$ values increased by $12 \%$ for $3 \%$ barium titanate additive ratio compared to REF-B coded fabric. When the reflectance results of sateen weave fabrics were investigated, it was shown that visible reflectance $\left(R_{V}\right)$ values increased by $9 \%$ and the solar reflectance $\left(\mathrm{R}_{\mathrm{S}}\right)$ values increased by $5 \%$ for $3 \%$ barium titanate additive ratio compared to REF-S coded fabric. When the reflectance results of special weave fabrics were investigated, it was shown that visible reflectance $\left(R_{V}\right)$ values increased by $10 \%$ and the solar reflectance $\left(\mathrm{R}_{\mathrm{S}}\right)$ values increased by $5 \%$ for $3 \%$ barium titanate additive ratio compared to REF-O coded fabric. In all regions, the highest reflectance values $68.18 \%\left(\mathrm{R}_{\mathrm{V}}\right)$ and $62.80 \%\left(\mathrm{R}_{\mathrm{S}}\right)$ were obtained with maximum barium titanate additive ratio at plain weave fabric structure. The results showed that the changes in the fabric structure did not cause a significant effect on the solar properties of woven fabrics. 
Table 5. Spectrophotometry results

\begin{tabular}{|c|c|c|c|c|c|}
\hline $\begin{array}{l}\text { Fabric } \\
\text { Code }\end{array}$ & $\begin{array}{l}\mathrm{T}_{\mathrm{UV}} \% \\
(280-380 \mathrm{~nm})\end{array}$ & $\begin{array}{l}\mathbf{T}_{\mathbf{V}} \% \\
(380-780 \mathrm{~nm})\end{array}$ & $\begin{array}{l}\mathbf{R}_{\mathbf{V}} \% \\
(380-780 \mathrm{~nm})\end{array}$ & $\begin{array}{l}T_{S} \% \\
(300-2500 \mathrm{~nm})\end{array}$ & $\begin{array}{l}\mathbf{R}_{\mathrm{S}} \% \\
(300-2500 \mathrm{~nm})\end{array}$ \\
\hline REF-B & 9.90 & 37.62 & 59.23 & 37.98 & 56.29 \\
\hline $1 B$ & 3.00 & 32.21 & 63.56 & 33.55 & 58.73 \\
\hline 2B & 2.15 & 31.62 & 65.86 & 33.30 & 60.07 \\
\hline 3B & 2.14 & 30.39 & 68.18 & 31.94 & 62.80 \\
\hline REF-S & 9.58 & 34.87 & 61.50 & 34.94 & 58.06 \\
\hline $1 S$ & 3.06 & 30.62 & 66.22 & 31.28 & 61.11 \\
\hline $2 S$ & 2.43 & 30.63 & 67.34 & 31.97 & 61.59 \\
\hline $3 S$ & 2.21 & 29.35 & 66.78 & 30.93 & 61.17 \\
\hline REF-O & 10.51 & 38.15 & 60.10 & 38.35 & 57.51 \\
\hline 10 & 3.09 & 32.24 & 64.57 & 33.47 & 59.82 \\
\hline 20 & 2.17 & 30.63 & 66.27 & 32.49 & 60.69 \\
\hline 30 & 2.10 & 29.34 & 66.01 & 31.03 & 60.55 \\
\hline
\end{tabular}

\section{CONCLUSION}

In this study, sheet resistance, electromagnetic shielding and solar properties of woven fabrics, which were produced barium titanate/polyester core/sheath bicomponent yarns were investigated. The effect of barium titanate additive ratio and the fabric structure on sheet resistance, electromagnetic shielding and solar properties were evaluated.

The addition of barium titanate caused a small increase in the melting temperature of bicomponent yarns. With the increasing additive ratio, the sheet resistance values slightly decreased. The lowest sheet resistance value was obtained for the $3 \%$ barium titanate added sateen fabric.

Barium titanate had a positive effect on the shielding efficiency of woven fabrics. Compared to the reference fabrics, EMSE values increased by $92 \%, 93 \%$ and $94 \%$ at $15 \mathrm{MHz}$ for plain, sateen and special weave fabric, respectively. In future works, different woven fabrics will be produced using barium titanate and carbon-based additive bicomponent yarns to provide higher SE values for general use according to the FTTS standard. On the other

\section{REFERENCES}

1. Malik P, Sharma A, Gianender, Sharma JP. 2018. Textiles for protection against electromagnetic radiations: A review. Pratibha Malik Journal of Engineering Research and Application, 8(6), 32-37.

2. Bonaldi RR, Siores E, Shah T. 2014. Characterization of electromagnetic shielding fabrics obtained from carbon nanotube composite coatings. Synthetic Metals, 187, 1-8.

3. Chen AP, Lin CM, Lin CW, Hsieh CT, Lou CW, Young YH, Lin JH, 2010. Electromagnetic shielding effectiveness and manufacture technique of functional bamboo charcoal/metal composite woven. Advanced Materials Research, 123, 967-970.

4. Das A, Kothari VK, Kothari A, Kumar A. 2009. Effect of various parameters on electromagnetic shielding effectiveness of textile fabrics. Indian Journal of Fibre \&Textile Research, 34, 144-148.

5. Maity S, Chatterjee A. 2018. Conductive polymer-based electroconductive textile composites for electromagnetic interference shielding: A review. Journal of Industrial Textiles, 2018; 47. 8: 2228-2252.

6. Neruda M, Vojtech L. 2014. Modelling of conductive textile materials for shielding purposes and RFID textile antennas. Elektronika IR Elektrotechnika, 20(8), 63-67. hand, the barium titanate additive improved visible and solar reflectance properties. In the highest barium titanate additive ratio, the highest decrease rate in solar transmittance was $19 \%$ for special weave fabric. In contrast, the highest increase rate of solar reflectance was $5 \%$ for plain weave fabric.

This study showed that woven fabrics produced from barium titanate added bicomponent yarns could provide improvements electromagnetic shielding and solar reflectance, which were one of the most important issues in the technical textile industry. Barium titanate can be preferable due to its unique properties such as low cost, environmentally friendly, etc. and as it provides multifunctional properties to textile products.

\section{Acknowledgement}

The authors wish to thank M.Sc. Olcay TOK and M.Sc. Onur CELEN for their contribution in the production of woven fabrics. The authors thank to Assoc. Prof. Dr. Erhan SANCAK, Res. Assist. Gizem MANASOGLU and Bursa Technical University Central Research Laboratory for their contributions and supports.

7. Ott HW, Ott HW. 1988. Noise reduction techniques in electronic systems. New York: Wiley.

8. Chen KB, Lee KC, Ueng TH, Mou KJ. 2002. Electrical and impact properties of the hybrid knitted inlaid fabric reinforced polypropylene composites, Composites Part A, 33(9), 1219-1226.

9. Cheng KB, Cheng TW, Lee KC, Ueng TH, Hsing WH. 2003. Effect of yarn constituent and fabric specifications on electrical properties of hybrid woven fabrics, Composites Part A, 34(10), 971-978.

10. Dordevic Z. 1992. Textile fabric shielding electro-magnetic radiation and clothing made thereof. 5,103,504. U.S.

11. Lin ZI, Lou CW, Pan Y J, Hsieh CT, Huang CH, Huang CL, ..., Lin JH. 2017. Conductive fabrics made of polypropylene/multi-walled carbon nanotube coated polyester yarns: Mechanical properties and electromagnetic interference shielding effectiveness. Composites Science and Technology, 141, 74-82.

12. Gültekin BC. 2018. Evaluation of the electromagnetic shielding effectiveness of carbon-based screen printed polyester fabrics. Fibers and Polymers, 19(2), 313-320. 
13. Duran D, Kadoğlu H. 2015. Electromagnetic shielding characterization of conductive woven fabrics produced with silvercontaining yarns. Textile Research Journal, 85(10), 1009-1021.

14. Örtlek HG. Güneşoğlu C, Okyay G, Türkoğlu Y. 2012. Investigation of electromagnetic shielding and comfort properties of single jersey fabrics knitted from hybrid yarns containing metal wire. Journal $O f$ Textile \& Apparel, 22(2), 90-101.

15. Özdemir H, Özkurt A. 2013. The effects of weave and conductive yarn density on the electromagnetic shielding effectiveness of cellular woven fabrics. Journal Of Textile \& Apparel, 23(2).

16. Eren S, Ulcay Y. 2015. Production of bi-component polyester fibres for EMR (electromagnetic radiation) protection and examining EMR shielding characteristics. Journal Of Textile \& Apparel, 25(2).

17. Özen MS, Sancak E, Soin N, Shah TH, Siores E. 2016. Investigation of electromagnetic shielding effectiveness of needle punched nonwoven fabric produced from conductive silver coated staple polyamide fibre. The Journal of The Textile Institute, 107(7), 912-922.

18. Ni QQ, Melvin GJH, Natsuki T. 2015. Double-layer electromagnetic wave absorber based on barium titanate/carbon nanotube nanocomposites. Ceramics International, 41(8), 9885-9892.

19. Qiu J, Qiu T. 2015. Fabrication and microwave absorption properties of magnetite nanoparticle-carbon nanotube-hollow carbon fiber composites. Carbon, 81, 20-28.

20. Wang Z, Wu L, Zhou J, Cai W, Shen B, Jiang Z. 2013. Magnetite nanocrystals on multiwalled carbon nanotubes as a synergistic microwave absorber. The Journal of Physical Chemistry C, 117(10), 5446-5452.

21. Zhu Y-F, Ni Q-Q, Fu Y-Q. 2015. One-dimensional barium titanate coated multi-walled carbon nanotube heterostructures: synthesis and electromagnetic absorption properties RSC Advances, 5, 3748-3756.

22. Yusoff AN, Abdullah MH, Ahmad SH, Jusoh SF, Mansor AA, Hamid SAA. 2002. Electromagnetic and absorption properties of some microwave absorbers Journal of Applied Physics, 92, 876-882.

23. Melvin GJH, Ni QQ, Natsuki T. 2014. Electromagnetic wave absorption properties of barium titanate/carbon nanotube hybrid nanocomposites. Journal of Alloys and Compounds, 615, 84-90.

24. Melvin GJH. Ni QQ, Natsuki T, Wang Z, Morimoto S, Fujishige M,..., Endo M. 2015. Ag/CNT nanocomposites and their single-and double-layer electromagnetic wave absorption properties. Synthetic Metals, 209, 383-388.

25. Melvin GJH, Ni QQ, Suzuki Y, Natsuki T. 2014. Microwaveabsorbing properties of silver nanoparticle/carbon nanotube hybrid nanocomposites. Journal of Materials Science, 49(14), 5199-5207.

26. Saini P, Arora M, Gupta G, Gupta BK, Singh VN, Choudhary V. 2013. High permittivity polyaniline-barium titanate nanocomposites with excellent electromagnetic interference shielding response. Nanoscale, 5(10), 4330-4336.

27. Saini P, Arora M. 2013. Formation mechanism, electronic properties \& microwave shielding by nano-structured polyanilines prepared by template free route using surfactant dopants. Journal of Materials Chemistry A, 1(31), 8926-8934.

28. Ting TH, Jau YN, Yu RP. 2012. Microwave absorbing properties of polyaniline/multi-walled carbon nanotube composites with various polyaniline contents. Applied Surface Science, 58(7), 3184-3190.

29. Makeiff DA, Huber T. 2006. Microwave absorption by polyanilinecarbon nanotube composites. Synthetic Metals, 156(7-8), 497-505.

30. Vijatović MM, Bobić JD, Stojanović BD. 2008. History and challenges of barium titanate: part II. Science of Sintering, 403, 235-244.

31. Celen R, \& Ulcay Y. 2018. The use of barium titanate in electromagnetic shielding applications at textiles. Uludağ University Journal of The Faculty of Engineering, 23(2), 29-44.

32. Infante IC, Volkova H, Gemeiner P, Geneste G, Guillot J et al. 2018. Third Seminar on the Mechanics of Multifunctional Materials, BadHonnef, Germany.
33. Sharma S, Tomar M, Puri NK, Gupta V. 2015. Ultraviolet radiation detection by barium titanate thin films grown by sol-gel hydrothermal method. Sensors and Actuators A: Physical, 230, 175-181.

34. Kilic A, Shim E, Yeom BY, Pourdeyhimi B. 2013. Improving electret properties of PP filaments with barium titanate. Journal of Electrostatics, 711, 41-47.

35. Yu CR, Wu DM, Liu Y, Qiao H, Yu ZZ, Dasari A,..., Mai YW. 2011 Electrical and dielectric properties of polypropylene nanocomposites based on carbon nanotubes and barium titanate nanoparticles. Composites Science and Technology, 7115, 1706-1712.

36. Cai MQ, Yin Z, Zhang MS. 2003. First-principles study of optica properties of barium titanate. Applied Physics Letter, 83(14), 2805 2807.

37. Xiang B, Zhang J. 2018. A new member of solar heat-reflective pigments: $\mathrm{BaTiO}_{3}$ and its effect on the cooling properties of ASA (acrylonitrile-styrene-acrylate copolymer). Solar Energy Materials and Solar Cells, 180,67-75.

38. Cai W, Fu C, Gao J, Guo Q, Deng X, Zhang C. 2011. Preparation and optical properties of barium titanate thin films. Physica B: Condensed Matter, 406(19), 3583-3587.

39. Celen R, Ulcay Y. 2019. Investigating electromagnetic shielding effectiveness of knitted fabrics made by barium titanate/polyester bicomponent yarn. Journal of Engineered Fibers and Fabrics, 14, 1558925019837806

40. Committee for Conformity Assessment of Accreditation and Certification on Functional and Technical Textiles. 2005. Specified requirements of electromagnetic shielding textiles.(Standard No. FTTS-FA-003). Taipei/Taiwan.

41. Yildirim K, Kanber A, Karahan M, Karahan N. 2018. The solar properties of fabrics produced using different weft yarns. Textile Research Journal, 88(13), 1543-1558.

42. Kim B, Koncar V, Devaux E, Dufour C, Viallier P. 2004. Electrical and morphological properties of PP and PET conductive polymer fibers. Synthetic Metals, 146(2), 167-174.

43. Yu B, Qi L, Ye JZ, Sun H. 2007. Preparation and radar wave absorbing characterization of bicomponent fibers with infrared camouflage. Journal of Applied Polymer Science, 104(4), 2180-2186.

44. Tezel S, Kavușturan Y, Vandenbosch GA, Volski V. 2014 Comparison of electromagnetic shielding effectiveness of conductive single jersey fabrics with coaxial transmission line and free space measurement techniques. Textile Research Journal, 845, 461-476.

45. Ortlek HG. Kilic G, Okyay G, Bilgin S. 2011. Electromagnetic shielding characteristics of different fabrics knitted from yarns containing stainless steel wire. Industria Textila, 62(6), 304-308.

46. Lin JH, Lou CW, Liu HH. 2007. Process and anti-electrostatic properties of knitted fabric made from hybrid staple/metallic-core spun yarn. Journal of Advanced Materials, 39(1), 11-16.

47. Liu Z, Wang XC. 2012. Influence of fabric weave type on the effectiveness of electromagnetic shielding woven fabric. Journal of Electromagnetic Waves and Applications, 26(14-15), 1848-1856.

48. Okyay G, Bilgin S, Akgul E, Ortlek HG. 2011. Farklı yapılardaki dokuma kumaşların elektromanyetik ekranlama özelliklerinin incelenmesi. Tekstil Teknolojileri Elektronik Dergisi, 5(1), 1-10.

49. Su J, Zhang J. 2016. Preparation and properties of barium titanate (BaTiO3) reinforced high density polyethylene (HDPE) composites for electronic application. Journal of Material Science, 27(5), 43444350 .

50. Qing Y, Mu Y, Zhou Y, Luo ., Zhu D, Zhou W. 2014. Multiwalled carbon nanotubes- BaTiO3/silica composites with high complex permittivity and improved electromagnetic interference shielding at elevated temperature. Journal of the European Ceramic Society, 34, $2229-2237$.

51. Melvin GJH, Ni QQ, Wang Z. 2017. Performance of barium titanate@carbon nanotube nanocomposite as an electromagnetic wave absorber. Physica Status Solidi A, 214(2), 160054. 